Original Research

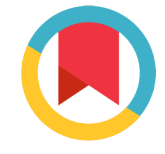

Check for updates

\section{*For corresp4ndence:}

a.ismail@su.edu.sa

Competing interests: The authors declare that no competing interests exist.

Received: 30 September 2017 Accepted: 05 November 2017 Published: 29 November 2017

Copyright The Author(s) 2017. This article is published with open access by BioMedPress.

This article is distributed under the terms of the Creative Commons Attribution License (CC-BY 4.0) which permits any use, distribution, and reproduction in any medium, provided the original author(s) and the source are credited.

\section{The relationship between some biochemical and hematological changes in type 2 diabetes mellitus}

\section{Zafer Saad Al Shehri}

Clinical Laboratory Department, Al-Dawadmi College of Applied Medical Sciences, Shaqra University -KSA

\section{Abstract}

Introduction: The aim of this study was to investigate various biochemical and hematological parameters in patients with type 2 diabetes mellitus (T2DM) and compare those with non-diabetic subjects (control group). Subjects: The study was conducted on 405 subjects (ages ranging from 26-65 years old; sex matched) who were classified into two groups: diabetic ( $n=205$ subjects; males-105, females-100) and non-diabetic subjects ( $n=200$; males-100, females-100). The study was carried out during the period of November 2016 to April 2017 in the Department of Clinical Laboratory Sciences at the College of Applied Medical Science Al-Dawadmi, Shaqra University in Saudi Arabia (with the collaboration of the General Hospital Al-Dawadmi). Methods: The following various parameters were assessed for all subjects: body mass index (BMI), systolic and diastolic blood pressure (SBP-DBP), fasting blood sugar (FBS), serum glutamic pyruvic transaminase (SGPT), alkaline phosphatise (ALP), total cholesterol (T. Ch), triglyceride (TG), low-density lipoprotein (LDL), high density lipoprotein (HDL), hemoglobin (HB), red blood cell count $(\mathrm{RBC})$, hematocrit $(\mathrm{Ht})$, mean corpuscular volume (MCV), mean corpuscle hemoglobin concentration $(\mathrm{MCHC})$, mean corpuscular hemoglobin $(\mathrm{MCH})$, red cell distribution width (RDW), platelet count (PIt), mean platelet volume (MPV), platelet distribution width (PDW), total white blood cell count (WBC), lymphocyte count (L), neutrophil count $(\mathrm{N})$, eosinophil count $(\mathrm{E})$, monocyte count (M), basophil count (B), neutrophil/lymphocyte ratio (N/L), and platelet/lymphocyte ratio (P/L). Results: The results showed an increase in the mean values of SGPT, alkaline phosphatase, urea, serum creatinine, total cholesterol, triglyceride, and LDL in the T2DM group relative to the control group. Meanwhile, the mean value of HDL was significantly decreased in the T2DM group compared to the control group $(p<0.05)$. The mean values of hemoglobin, $\mathrm{RBC}, \mathrm{MCV}, \mathrm{MCHC}$ and $\mathrm{MCH}$ were significantly decreased in the T2DM group compared to the control group. In contrast, the red cell distribution width significantly increased in the T2DM group versus control group $(p<0.05)$. 
The mean platelet count was not significantly changed in the T2DM group compared to the control group ( $p>0.05$ ), but the mean values of PDW and MPV were significantly higher in the T2DM group compared to the control group $(p<0.05)$. The mean white blood cell count and differential white blood cell was significantly higher in the T2DM group compared to control group $(p<0.05)$. Lastly, the mean neutrophil/lymphocyte ratio and platelet/lymphocyte ratio was not significantly different in the T2DM group compared to control group ( $p>0.05)$. Conclusion: In diabetes mellitus type 2 patients, certain biochemical and hematological changes are distinct from healthy subjects. It is important to follow up and monitor these parameters carefully in diabetic patients.

\section{Keywords}

Complete blood count, Diabetes mellitus type 2, Kidney function, Lipid profile, Liver function

\section{Introduction}

Diabetes mellitus is a very common endocrinal disorder affecting a majority of the world population and reaching to epidemic proportions in some countries (Guariguatart al., 2013). In Saudi Arabia, diabetic patients are increasing day by day and these may be due to shifts in lifestyle, increase rates of consumption of fast foods and beverages containing high levels of sugars (e.g. sodas), lack of exercise, unhealthy diet, obesity, obesity, and socioeconomic changes over the past four decades (Zahid 2015).

Diabetes mellitus can be defined as a group of metabolic disorders that are characterized by several defects in the regulation of carbohydrate, fat or protein metabolism, or all of the above (Guyton et al., 2002). Diabetes mellitus is characterized by hyperglycemia, glycosuria, hyperlipidemia, and negative nitrogen balance. Hyperglycemia in diabetes mellitus results from defects in insulin secretion or function, or both. The metabolic deregulation may be associated with secondary damage to multiple organ systems, especially the nerves, eyes, blood vessels and kidneys. The incidence of diabetes mellitus is on the rise worldwide (Aslan et al., 2006).

The relationship between some components of metabolic syndromes and leukocytes was noted in several epidemiological studies that showed an association between total white blood cell count (WBC) and diabetes mellitus (Barzilay et al., 2001). Leukocyte plays an important role during inflammation and also play some roles in the development of diabetes (Fu-Mei et al, 2005). There are common findings of reduced hemoglobin concentrations in diabetic patients (Thomas et al, 2003). The liver plays an important role in carbohydrate metabolism as it has the capability to store glucose as glycogen and synthesize 
glucose from non-carbohydrate sources (Levinthal and Tavill, 1999). Increased activities of liver enzymes such as aspartate aminotransferase (AST) and alanine aminotransferase (ALT) are indicators of hepatocellular injury and also associated with insulin resistance (Marchesiri et al, 2001), metabolic syndrome and type 2 diabetes (Sattar et al, 2004 and Wannamethee et al, 2005). Diabetic patients may have induced dyslipidemia. Dyslipidemia is characterized by elevated levels of total cholesterol, triglycerides, low levels of $\mathrm{HDL}$, and increased low-density lipoprotein (LDL) (Nakanishi et al, 2005).

In the present study we aim to study various biochemical and hematological changes among Type 2 diabetes mellitus patients in Saudi Arabia.

\section{Materials-Methods}

\section{Study subjects}

This study consisted of 405 subjects (ages ranging from 26-65 years; sex matched) who were classified into two groups. The first group consisted of diabetic patients ( $n=205$; males-105, females-100) and the second group consisted of non-diabetic subjects ( $n=200$; males-100, females-100). The study was carried out during the period of November 2016 to April 2017 in the Department of Clinical Laboratory Sciences at the College of Applied Medical Science Al-Dawadmi, Shaqra University in Saudi Arabia (with the collaboration of the General Hospital Al-Dawadmi). All diabetes mellitus cases were clinically diagnosed by a specialized clinician. The patients were admitted to the General Hospital Al-Dawadmi. Patients with defective renal or hepatic diseases, acute infections and/or hematologic diseases with WBC count $>15,000 / \mathrm{mm}^{3}$ were excluded. Height and weight were measured using height and weight scales in ZT-120. BMI was calculated as weight in kilograms divided by height in meters squared. Any BMI values from 23.0-24.9 kg/m² were considered as overweight and $>25.0 \mathrm{~kg} / \mathrm{m}^{2}$ as obese (WHO 2000).

\section{Ethics approval and consent}

The study was conducted after ethics approval from the Institutional Ethical Committee of Shaqra University, and all participants signed an informed consent form before the study assessments.

\section{Laboratory evaluations}

Consent was taken from every subject and they were requested to fast overnight (10 to $12 \mathrm{hrs}$ ). Blood samples were collected by venipuncture from non-diabetic and diabetic subjects. The serum samples were separated after allowing them to clot by centrifugation at 2500 rpm for 10 minutes at room temperature and were 
stored at $-20^{\circ} \mathrm{C}$ until tested. Blood samples were treated as follows: for SGPT/ ALT, total cholesterol, urea \& creatinine estimation $4 \mathrm{~mL}$ of whole blood was taken in a plain test tube and serum was separated by centrifugation at 2500 rpm. However, in the case of glucose testing, $2 \mathrm{~mL}$ of blood was taken into a separate test tube containing fluoride fluid and within one hour of sample collection, plasma was separated. For estimation of CBC, $2 \mathrm{~mL}$ of blood was taken in a separate test tube containing ethylene di-amino tetra acetic acid (EDTA). Complete blood counts (including WBC, differential count and hemoglobin) were performed in an automatic counting machine (Cell-Dyn Ruby, Abbott Inc., Illinois, USA; Sysmex 1800i, Japan). Plasma glucose and other biochemical parameters (SGPT/ALT, total cholesterol, urea, and creatinine) were measured in the BIRDEM Biochemistry Laboratory, Dhaka, by the following mentioned methods.

\section{Biochemical and Hematological Evaluations}

The levels of fasting blood sugar (FBS), total cholesterol, SGPT/ALT, urea, and creatinine were measured by commercially available kits (Bio-Rad Laboratories, Richmond, USA; Randox laboratories Ltd., Antrim, UK; Merck, Germany; Sigma Chemicals Co., USA; Roche international Inc., USA; Johnson \& Johnson Inc., New Jersey, USA) by Dade Behring, Hitachi-912 and Vitros-250 (Dry Chemistry) automated chemistry analyzers. The glucose test was done with the modified hexokinase-glucose-6-phosphate dehydrogenase method, presented as a general clinical laboratory method by Kunst et al. (Kunst $A$ at al., 1983). The normal values are as follows: SGPT/ALT (up to $40 \mathrm{U} / \mathrm{L}$ ), urea (10-50 mg/dL), creatinine $(0.67-1.2 \mathrm{mg} / \mathrm{dL})$, and total cholesterol $(<200 \mathrm{mg} / \mathrm{dL})$. The normal hematological parameters are as follows: WBC $(4000-10,500 / \mathrm{cm})$, hemoglobin (males: 13-17 g/dL; females: 12-15 g/dL), ESR (males: <10; females: $<20 \mathrm{~mm}$ in $1^{\text {st }} \mathrm{hr}$ (western green)), differential counts for neutrophil (40-70\%), lymphocytes (20-45\%), monocytes (2-8\%), and eosinophils (1-5\%). All biochemical tests were done at $37^{\circ} \mathrm{C}$.

\section{Statistical Analysis}

Statistical Package for Social Sciences version 19.0 was used to perform the statistical analyses. The data were expressed as mean \pm SD or expressed as \%. The mean values were tested for significance using a test for paired samples, the Student's t-test and Mann-Whitney U test. Pearson's Chi-square test was also used to compare the categorical variables between these two groups. To determine the relationship between $N$ and $L$ in the $N / L$ ratio, the Spearman correlation analysis was used. The values was regarded as statistically significant when $\mathrm{P}<0.05$. 


\section{Results}

\section{Demographic and characteristics of the study participants}

The results showed that the mean levels of systolic and diastolic blood pressure (BP) levels were significantly higher in T2DM patients than in the healthy, nondiabetic (control) group $(P<0.05)$; the body mass index showed a nonsignificant difference between the two groups (Table 1; Fig. 1).

Table 1. Demographic findings and characteristics of the study participants

\begin{tabular}{|c|c|c|c|c|c|}
\hline Parameter & Unit & Reference range & $\begin{array}{c}\text { T2DM } \\
(\mathbf{M} \pm \mathbf{S D})\end{array}$ & $\begin{array}{c}\text { Controls } \\
(\mathbf{M} \pm \text { SD) }\end{array}$ & P-value \\
\hline Age & years & - & $45.5 \pm 5.5$ & $46.8 \pm 4.8$ & 0.112 \\
\hline BMI & $\mathrm{kg} / \mathrm{m} 2$ & $\begin{array}{c}\text { overweight: }>23.0 \text { to } 24.9 ; \\
\text { obese: }>25.0 \mathrm{~kg} / \mathrm{m} 2\end{array}$ & $22.36 \pm 1.4$ & $21.9 \pm 1.87$ & 0.006 \\
\hline SBP & $\mathrm{mm} \mathrm{Hg}$ & $<120$ & $138.9 \pm 3.4^{\star}$ & $121.4 \pm 3.1^{\star}$ & 0.041 \\
\hline DBP & $\mathrm{mm} \mathrm{Hg}$ & $<80$ & $88.2 \pm 1.62^{\star}$ & $76.3 \pm 1.8^{\star}$ & 0.036 \\
\hline
\end{tabular}

Data are presented as mean \pm standard deviation; ${ }^{*} p<0.05,{ }^{* *} p<0.01$.

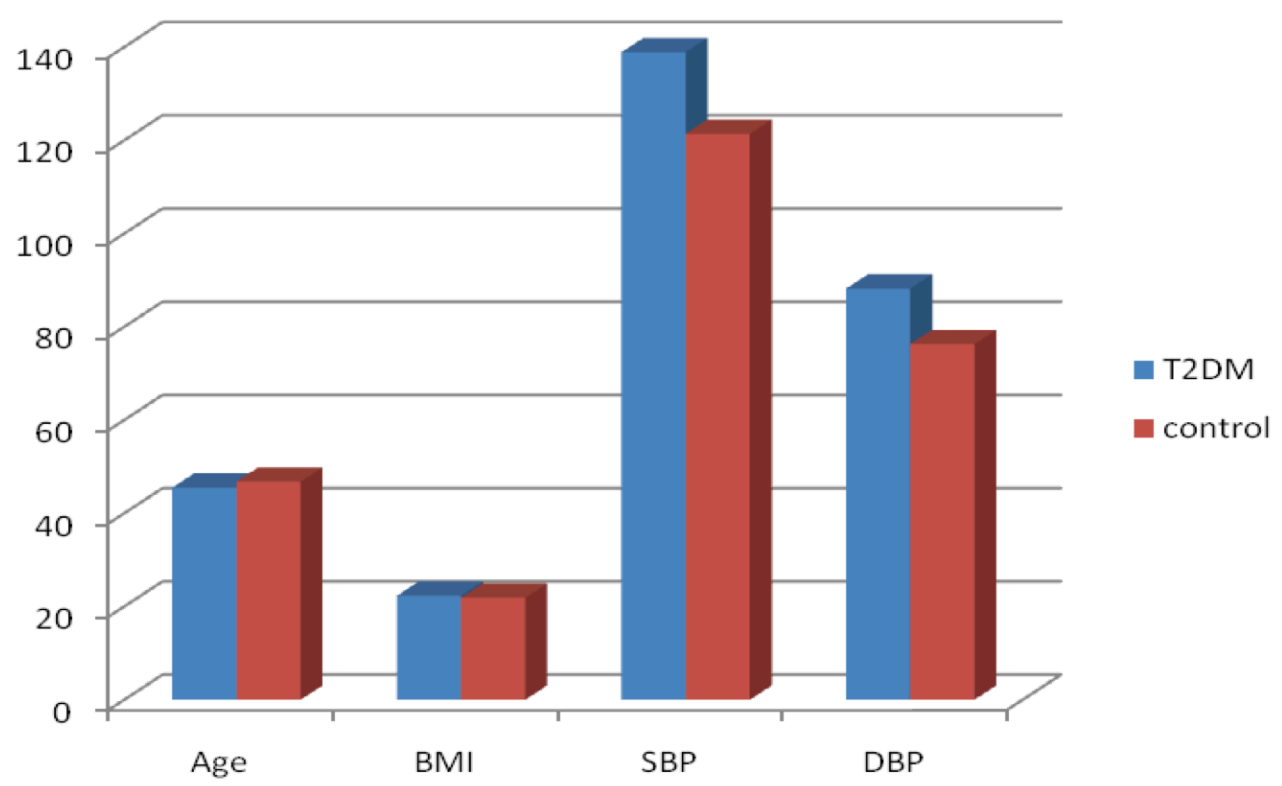

Figure 1. Demographic and characteristics of the study participants. 
A

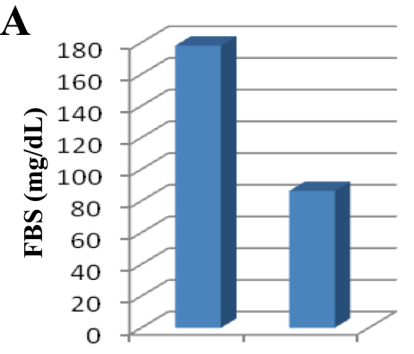

T2DM Control

D

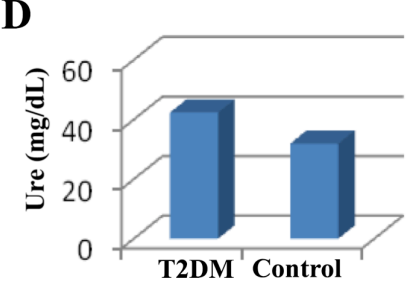

$\mathbf{G}$

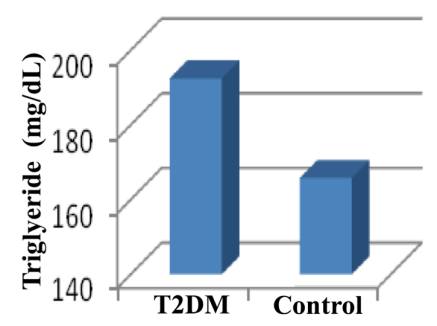

B
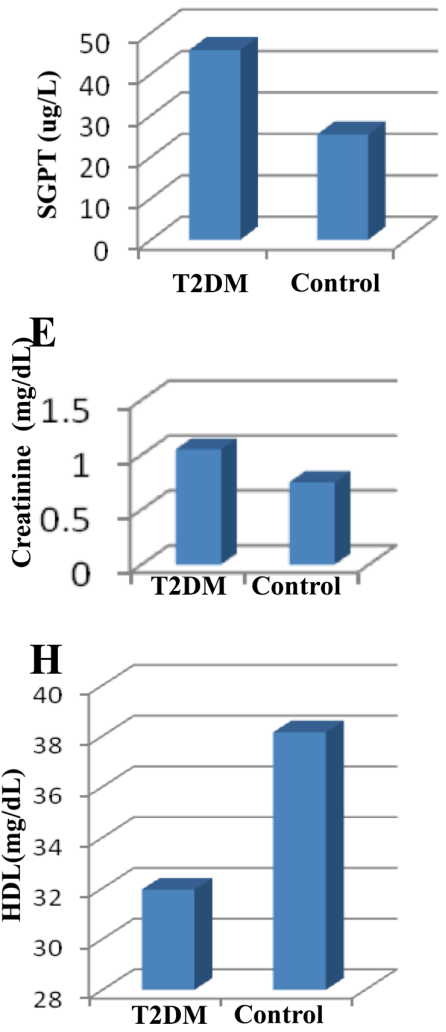

C

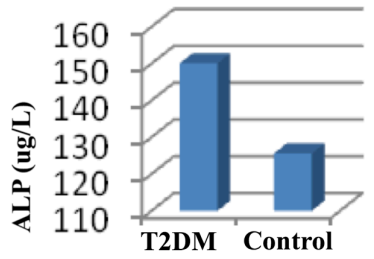

$$
\text { F }
$$
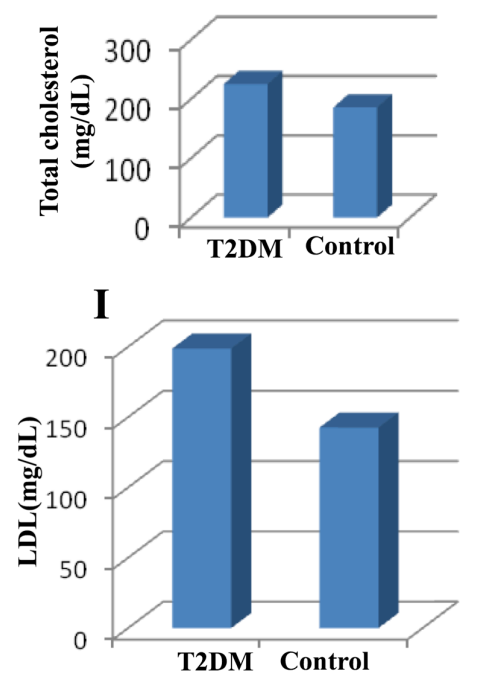

Figure 2. Biochemical laboratory results. The (mean $\pm S D$ ) of FBS, SGPT, alkaline phosphatase, urea, serum creatinine, total cholesterol, triglyceride, HDL and LDL in the T2DM group relative to the control group.

Table 2. Biochemical assessments for T2DM and control subjects

\begin{tabular}{|c|c|c|c|c|c|}
\hline Parameter & Unit & Reference range & $\begin{array}{c}\text { T2DM } \\
(\mathrm{M} \pm \mathrm{SD})\end{array}$ & $\begin{array}{l}\text { Controls } \\
(M \pm S D)\end{array}$ & P-value \\
\hline FBS & $\mathrm{mg} / \mathrm{dL}$ & $70-110$ & $178.2 \pm 14.55^{\star \star}$ & $86.4 \pm 5.32^{\star \star}$ & $<0.001$ \\
\hline SGPT & $u / L$ & up to 45 & $45.8 \pm 6.30^{\star}$ & $25.4 \pm 2.87^{\star}$ & 0.038 \\
\hline ALP & $u / L$ & 80-306 & $150.1 \pm 4.2^{\star}$ & $125.6 \pm 3.25^{\star}$ & 0.021 \\
\hline Urea & $\mathrm{mg} / \mathrm{dL}$ & $<50$ & $42.3 \pm 2.8^{*}$ & $31.9 \pm 1.5^{\star}$ & 0.024 \\
\hline Creatinine & $\mathrm{mg} / \mathrm{dL}$ & $<1.5$ & $1.05 \pm 0.045^{\star \star}$ & $0.75 \pm 0.05^{\star \star}$ & 0.009 \\
\hline T. Ch & $\mathrm{mg} / \mathrm{dL}$ & $>200$ & $225.36 \pm 5.42^{\star}$ & $186 \pm 4.22^{\star}$ & 0.042 \\
\hline TG & $\mathrm{mg} / \mathrm{dL}$ & $>150$ & $192.53 \pm 4.24^{\star}$ & $165.8 \pm 3.63^{\star}$ & 0.038 \\
\hline HDL & $\mathrm{mg} / \mathrm{dL}$ & $<40$ & $31.95 \pm 2.11^{\star}$ & $38.15 \pm 1.15^{\star}$ & 0.047 \\
\hline LDL & $\mathrm{mg} / \mathrm{dL}$ & $>130$ & $198.8 \pm 6.34^{*}$ & $142.6 \pm 5.17 *$ & 0.012 \\
\hline
\end{tabular}




\section{Biochemical laboratory assessments}

The results showed that there was an increase in the T2DM group compared to the control group with respect to the the mean values of the following parameters (values indicated): SGPT $(45.8 \pm 6.30)$, alkaline phosphatise $(150.1 \pm 4.2)$, urea $(42.3 \pm 2.8)$, creatinine $(1.05 \pm 0.045)$, total cholesterol (225.36 \pm 5.42$)$, triglyceride (192.53 \pm 4.24$), L D L(198.8 \pm 6.34)$ for the T2DM group, versus (25.4 \pm 2.87$),(125.6 \pm 3.25),(31.9 \pm 1.5),(0.75 \pm 0.05),(186 \pm 4.22)$, (165.8 \pm 3.63$)$, and (142.6 \pm 5.17$)$, respectively, for the control group (Table 2; Fig. $2 \mathrm{~A}-\mathrm{H})$. Meanwhile, the mean value of $\mathrm{HDL}$ for the T2DM group (31.95 \pm 2.11$)$ was significantly lower compared to that of the control group (38.15 \pm 1.15$)$ (Table 2; Fig. 2I).

\section{Hematological parameters of diabetes mellitus patients}

The mean values of hemoglobin, $\mathrm{RBC}, \mathrm{MCV}, \mathrm{MCHC}$, and $\mathrm{MCH}$ significantly decreased $(p<0.05)$ in the T2DM group compared to the control group; the respective values were $(11.89 \pm 1.25),(4.32 \pm 0.75)(81.45 \pm 3.1),(26.4 \pm 2.87)$ and $(29.8 \pm 3.1)$ for the T2DM group, compared to $(12.69 \pm 1.96),(4.72 \pm 0.96)$, (85.63 \pm 5.2$),(27.47 \pm 3.6)$ and $(32.52 \pm 2.29)$ for the control group (Table 3; Fig. $3 A-F)$. In contrast, the RDW showed a significant increase $(p<0.05)$ in the T2DM group (14.57 \pm 3.1 ), compared to the control group (12.63 \pm 2.58 ) (Table 3; Fig. $3 \mathrm{G})$.

For the T2DM group, the mean platelet count (278.5 \pm 23.5$)$, mean PDW (18.76 \pm 1.72$)$, and MPV (11.94 \pm 1.36$)$ were all significantly higher than for healthy persons, whose parameters were $(245.3 \pm 17.5),(16.89 \pm 1.33)$ and $(10.058 \pm 1.2)$, respectively (Table 3; Fig $3 \mathrm{H}-\mathrm{J})$. The mean white blood cell count was significantly lower $(p<0.05)$ for the T2DM group (7.89 \pm 1.52$)$ than control group (6.92.15 \pm 1.74$)$. Moreover, the differential white blood cell count in terms of percentage of neutrophils, lymphocytes, eosinophils, monocytes and basophils were also significantly lower in the T2DM group; the respective values for each were (51.11 \pm 4.1$),(41.9 \pm 3.9),(4.15 \pm 0.56),(7.89 \pm 0.95)$ and $(0.8 \pm 0.02)$, as compared to the control group whose values were $(45.3 \pm 5.2),(37.1 \pm 4.58)$, $(2.11 \pm 0.41)$, $(5.1 \pm 0.84)$ and $(0.4 \pm 0.01)$, respectively $(p<0.05)$ (Table 3; Fig. 3KQ).

The mean neutrophil/lymphocyte $(\mathrm{N} / \mathrm{L})$ ratio and platelet/lymphocyte $(\mathrm{P} / \mathrm{L})$ ratio were not significantly different for the T2DM group compared to the control group. The respective parameters/values for the T2DM group were: N/L $(1.21 \pm 0.07)$ and $P / L(6.64 \pm 0.5)$; for the control group the values were $(1.22 \pm 0.15)$ and (6.61 \pm 0.3$)$, respectively ( $p>0.05$ ) (Table 3; Fig. 3S-3R). 
Table 3. Hematological laboratory results

\begin{tabular}{|c|c|c|c|c|c|}
\hline Parameter & Unit & Reference range & Diabetic Subjects & $\begin{array}{l}\text { Control } \\
\text { Subjects }\end{array}$ & P-value \\
\hline $\mathrm{HB}$ & $g / l$ & $12-16$ & $11.89 \pm 1.25$ & $12.68 \pm 1.96$ & 0.029 \\
\hline RBC & $\begin{array}{c}\times 106 / \\
\mu L\end{array}$ & $\begin{array}{l}\text { F 4.2-5.4×106 } \\
\text { M 4.6-6.19×106 }\end{array}$ & $4.32 \pm 0.75$ & $4.72 \pm 0.96$ & 0.045 \\
\hline $\mathrm{Ht}$ & $\%$ & $\begin{array}{l}\text { F 37-47 } \\
\text { M 40-54 }\end{array}$ & $33.9 \pm 2.2$ & $35.6 \pm 2.95$ & 0.075 \\
\hline MCV & $\mathrm{fL}$ & $76-96$ & $78.45 \pm 3.1^{\star}$ & $85.63 \pm 5.2^{\star}$ & 0.011 \\
\hline $\mathrm{MCH}$ & $\mathrm{Pg}$ & $27-34$ & $26.4 \pm 2.87^{\star}$ & $29.47 \pm 3.6^{\star}$ & 0.025 \\
\hline $\mathrm{MCHC}$ & $\mathrm{g} / \mathrm{dL}$ & $32-36$ & $29.8 \pm 3.1^{*}$ & $32.52 \pm 2.29 *$ & 0.036 \\
\hline RDW & $\%$ & $11 \%-14 \%$ & $14.57 \pm 3.1^{\star}$ & $12.63 \pm 2.58^{\star}$ & 0.047 \\
\hline Plt & $\mu \mathrm{L}$ & $140-440 \times 103 / \mathrm{mm}$ & $278.5 \pm 23.5^{\star}$ & $245.3 \pm 17.5^{\star}$ & 0.019 \\
\hline PDW & - & - & $18.76 \pm 1.72^{\star}$ & $16.89 \pm 1.33^{\star}$ & 0.029 \\
\hline MPV & $f L$ & $9-2.7$ & $11.94 \pm 1.36 *$ & $10.058 \pm 1.2^{\star}$ & 0.018 \\
\hline WBC & $\mu \mathrm{L}$ & $4-11 \times 103 / \mathrm{mm}$ & $8.9 \pm 1.52^{\star}$ & $6.92 \pm 1.74^{\star}$ & 0.025 \\
\hline $\mathbf{N}$ & $\%$ & $40-80$ & $51.11 \pm 4.1^{*}$ & $45.3 \pm 5.2^{\star}$ & 0.037 \\
\hline $\mathbf{L}$ & $\%$ & $20-40$ & $41.9 \pm 3.9^{*}$ & $37.1 \pm 4.58^{\star}$ & 0.042 \\
\hline$E$ & $\%$ & $1-6$ & $4.15 \pm 0.56^{\star}$ & $2.11 \pm 0.41 *$ & 0.044 \\
\hline M & $\%$ & $2-10$ & $7.89 \pm 0.95^{\star}$ & $5.1 \pm 0.84^{\star}$ & 0.016 \\
\hline B & $\%$ & $<1-2$ & $0.8 \pm 0.02^{\star}$ & $0.4 \pm 0.01 *$ & 0.028 \\
\hline$N / L$ & ratio & - & $1.21 \pm 0.07$ & $1.22 \pm 0.15$ & 0.083 \\
\hline$P / L$ & ratio & - & $6.64 \pm 0.5$ & $6.61 \pm 0.3$ & 0.071 \\
\hline
\end{tabular}


A

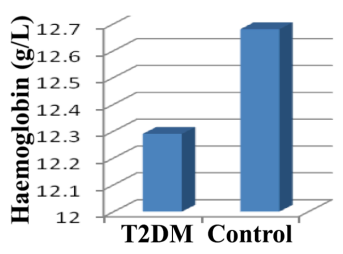

D

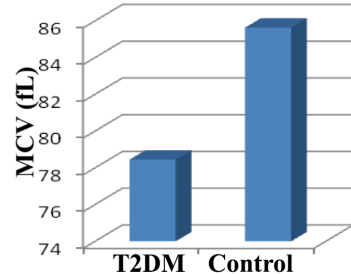

T2DM Control

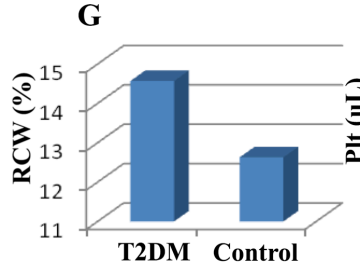

T2DM Control
B

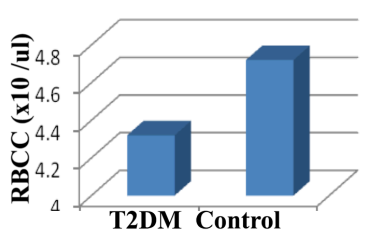

E

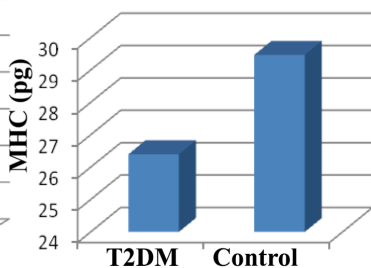

T2DM Control
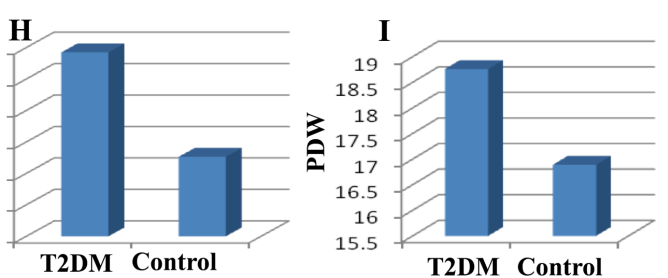

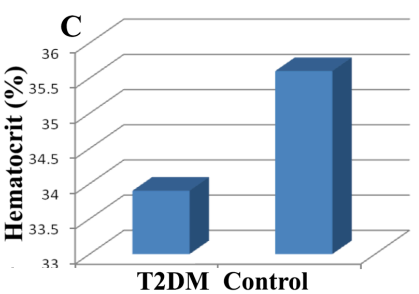

F

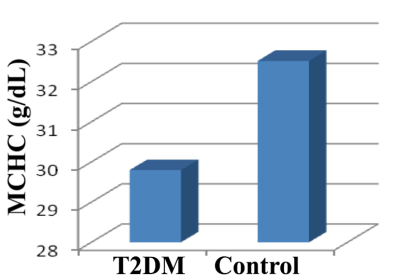

T2DM Control
K
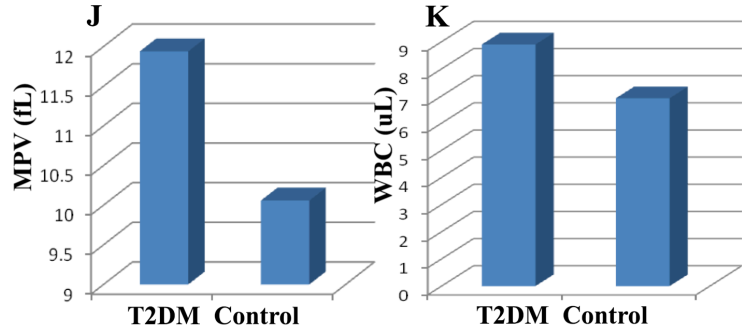

T2DM Control

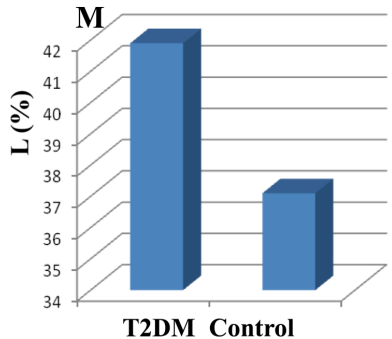

N $\quad$ O
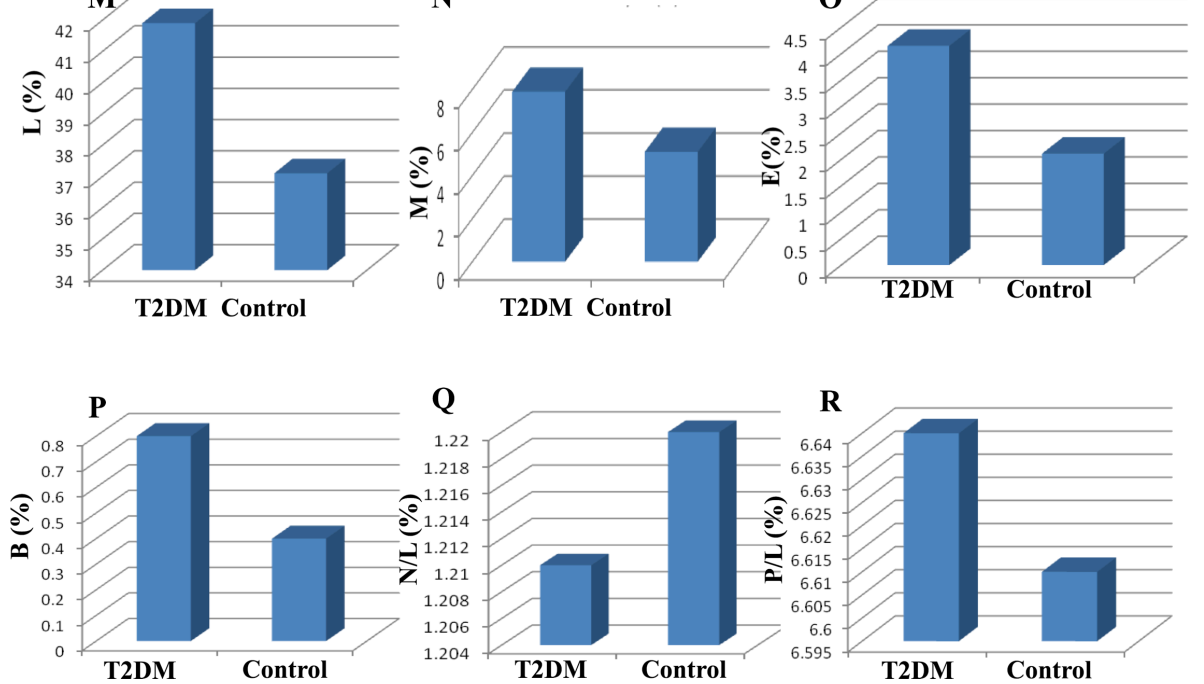

Q $\quad$ R

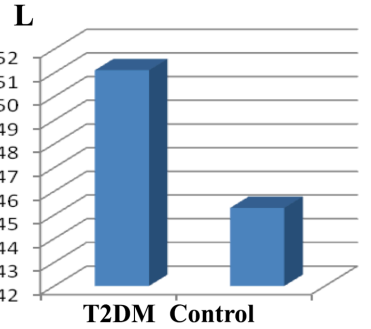

T2DM Contro

T2DM Control

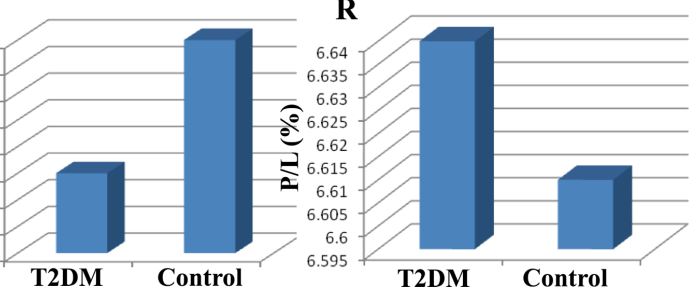

Figure 3. Mean values (mean \pm standard deviation) of hematological parameters for T2DM (type 2 diabetes mellitus) group and control group. Shown are data for Hemoglobin (A), Red blood cell count (B), Hematocrit (C), Mean corpuscular volume (D), Mean corpuscle hemoglobin (E), Mean 
corpuscular haemoglobin concentration (F), Red cell distribution width (ure), Platelet $(\mathbf{H})$, Platelet distribution width (I), Mean platelet volume (J), White blood cell (K), Neutrophil count (L), Lymphocyte count (M), Monocyte count (N), Eosinophil count $(\mathbf{O})$, Basophil count $(\mathbf{P})$, Neutrophil/lymphocyte ratio (Q), and platelet/lymphocyte ratio $(\mathbf{R})$.

\section{Discussion}

The results revealed that there is a strong relationship between increase of blood glucose sugar level and blood urea and serum creatinine levels; the increase may be due to damage in the kidney (Muragundla and Kanwaljitquercetin). The decrease in kidney function in diabetic patients may be due to several reasons including changes in urinary albumin excretion rate, glomerular filtration rate, and glycosylated hemoglobin (HbA1c) levels (Thomas al., 2003).

Hyperglycemia is one of the major causes of progressive renal damage. Diabetes is an epidemic disease and considered to be the most common cause of kidney disease. Typically, patients with diabetes should be investigated periodically for nephropathy and be assessed/monitored regularly for levels of serum creatinine, blood urea and urine albumin (Advance 2008).

The results of the study showed there was an increase in the mean values of SGPT and alkaline phosphatise. Similar studies have shown that type 2 diabetes is associated with a clinical spectrum of liver abnormalities and have found higher levels of GGT, ALT and ALK in the patients (Balogun 2008). In addition the study by Ohlson et al. (1988), it has been demonstrated that abnormal liver function (including increased levels of liver enzymes ALT and GGT) is frequently associated with type 2 diabetes mellitus. Control of blood sugar level is essential to prevent nephropathy; delaying it may cause many medical problems.

Moreover. the biochemical results in this study showed that there was an increase in the mean values of triglyceride, total cholesterol and LDL, whereas the mean value of HDL significantly decreased. Our results are consistent with those of previous studies which have indicated that diabetes is associated with increased lipolysis, triglyceride synthesis and hepatic uptake of free fatty acids, and with accumulation of hepatic triglycerides due to insulin resistance (Pagano 2002).

Furthermore, the results showed a decrease in the mean values of hemoglobin, red blood cell count, hematocrit, mean corpuscular volume, mean corpuscular hemoglobin, and mean corpuscular hemoglobin concentration in the T2DM patients versus the control group. Indeed, other studies have shown that several morphological changes in RBCs are strongly present in diabetic patients. Such changes include anisocytosis, poikilocytosis, and hypochromia; these changes may have a direct impact on erythrocyte function and may contribute to the 
patient's complex pathology (Neam et al., 2015). Many previous studies demonstrated that in uncontrolled T2DM patients, erythrocytes persist throughout their life span in the hyperglycemic environment and thus subjected to a series of changes which in turn affect their flow properties and functions (Sing et al., 2009). Other studies have shown that erythrocytes also suffer from alteration of oxygen affinity (Jones et al., 1981). Anaemia is common in patients with diabetes due to the high burden of chronic kidney disease (Thomas 2007), glycosylation of red blood cells membrane protein (Oyedemi et al., 2011), and several other defects found in the diabetic population (Weiss 2005) and (Arun 2002).

The study results demonstrated that levels of WBCs and differential leukocyte counts (including for neutrophils, lymphocytes, eosinophils, monocytes, and basophils) were slightly increased in T2DM patients compared to controls. The study by Vozarova et al., 2002 reported that there is relationship between WBC and diabetes mellitus as a result of increased inflammatory mediators. Inflammatory agents, insulin and human blood components form a critical signal for any abnormalities, resulting in invasion by foreign agents and/or inflammation (Ohshita et al., 2004). These latter factors can induce defense mechanisms and contribute to changes in levels of blood parameters, including mean white blood cell count, mean platelet count, and phagocyte percentage (Weyer et al., 2000).

Moreover, the study results showed an increase in the mean values of platelet, mean platelet volume, and platelet distribution width in diabetic patients compared to the control group. This increase may be a reflection of platelet activation. Many previous studies have demonstrated that platelets have large and variable sizes as can be observed in several clinical conditions, such as hemorrhage and myeloproliferative disorders. The increase may also indicate microvascular dysfunction (Beyan et al., 2006).

Our results are in agreement with other results which have shown that patients with diabetes mellitus show altered platelet function (such as high platelet counts and high MPV). It has been reported that diabetic patients are likely to experience an increased risk for vascular disease (Papanas 2004).

\section{Conclusion}

Type 2 diabetes mellitus is a serious public health problem. Underlying biochemical and hematological changes in T2DM patients may lead to the development of long-term complications and poor quality of life or death. Therefore, it is critical to follow up and monitor carefully biochemical and hematological parameters in diabetic patients. 


\section{Biomedical \\ Research \& Therapy}

ISSN: 2198-4093

\section{Abbreviations}

ALP: Alkaline phosphatase

$B$ : basophil count

BMI: body mass index

DBP: diastolic blood pressure

E: eosinophil count

FBS: fasting blood sugar

HB:hemoglobin

HDL: high-density lipoprotein.

$\mathrm{Ht}$ : hematocrit

L: lymphocyte

LDL: low-density lipoprotein

$\mathrm{M}$ : monocyte count

$\mathrm{MCH}$ : mean corpuscular hemoglobin

$\mathrm{MCHC}$ : mean corpuscular hemoglobin concentration

MCV: mean corpuscular volume

MPV: mean platelet volume

$\mathrm{N}$ : neutrophil count

N/L: neutrophil/lymphocyte ratio

$\mathrm{P} / \mathrm{L}$ : platelet/lymphocyte ratio.

PDW: platelet distribution width

Plt: platelet

RBC: red blood cell count

RDW: red cell distribution width

SBP: systolic blood pressure

SGPT: serum glutamic-pyruvic transaminase

T. Ch: total cholesterol

T2DM: type 2 diabetes mellitus

TG: triglyceride

WBC: white blood cell

\section{Acknowledgements}

I would like to thank Dr. Aly Ismail Aly, assistant professor and Mr. Zafar Akbar, both from Clinical Laboratory Science Department, Al-Dawadmi College of Applied Medical Sciences, Shaqra University -KSA for their great help in all steps related to this scientific investigational study. 


\section{References}

ADVANCE Collaborative Group. (2008). Intensive control of blood glucose and vascular outcomes in patients with type 2 diabetes. The New England Journal of Medicine, 358(24), 2560-2572. https://doi.org/10.1056/NEJMoa0802987

Arun, G. S., \& Ramesh, K. G. (2002). Improvement of insulin sensitivity by perindopril in spontaneously hypertensive and streptozotocindiabetic rats. Indian Journal of Pharmacology, 34, 156-164.

Aslant, M., Orhan, D. D., Orhan, N., Sezik, E., \& Yesilada, E. (2006). In vivo Antidiabetic and Antioxidant Potential of Helichrysum Plicatum ssp. In Streptozotocin induced diabetic rats. Journal of Ethnopharmacology, 109, 54-59. https://doi.org/10.1016/j.jep. $\underline{2006.07 .001}$

Balogun WO, Adeleye JO, Akinlade KS, Adedapo KS, Kuti M.Frequent. (2008). Occurrence of high gamma-glutamyl transferase and alanine amino transferase among Nigerian patients with type 2 diabetes. The African Journal of Medical Sciences, 37, 177-183.

Barzilay JI, Abraham L, Heckbert SR, Cushman M, Kuller LH, Resnick HE, Tracy RP (2001). The relation of markers of inflammation to the development of glucose disorders in the elderly: the Cardiovascular Health Study. Diabetes. Oct; 50(10):2384-9. https://doi.org/ 10.2337/diabetes.50.10.2384

Beyan, C., Kaptan, K., \& Ifran, A. (2006). Platelet count, mean platelet volume, platelet distribution width, and plateletcrit do not correlate with optical platelet aggregation responses in healthy volunteers. Journal of Thrombosis and Thrombolysis, 22(3), 161164. https://doi.org/10.1007/s11239-006-9014-7

Chung, F.-M., Tsai, J. C.-R., Chang, D.-M., Shin, S.-J., \& Lee, Y.-J., \& the Fu-mei Chung. (2005). Peripheral Total and Differential Leukocyte Count in Diabetic Nephropathy. Diabetes Care, 28(7), 1710-1717. https://doi.org/10.2337/diacare.28.7.1710

Guariguata, D. R., Whiting, D. R., Hambleton, I., Beagley, J., Linnenkamp, U., \& Shaw, J. E. (2014). Whiting, I. Hambleton, J. Beagley, U. Linnenkamp, and J. E. Shaw, "Global estimates of diabetes prevalence for 2013 and projections for 2035 [View at Publisher - View at Google Scholar · View at Scopus]. Diabetes Research and Clinical Practice, 103(2), 137-149. https://doi.org/10.1016/j.diabres.2013.11.002

Guyton, A. C., \& Hall, J. E. (2002). Medical Physiology (10th ed., pp. 797-801). London: W.B. Saunders.

Jones, R. L., \& Peterson, C. M. (1981). Hematologic alterations in diabetes mellitus. The American Journal of Medicine, 70(2), 339-352. https://doi.org/ 10.1016/0002-9343(81)90771-3

Kunst A, Drager B, Ziegenhorn J, (1983). UV methods with hexokinase and glucose-6phosphate dehydrogenasen, Methods of enzymatic Analysis, Vol. VI, Bergmeyer, HY, Ed, Verlag chemie Deerfield, FL., 163-172.

Levinthal, G. N., \& Tavill, A. J. (1999). Liver disease anddiabetes mellitus. Clinical Diabetes, 17, 73.

Marchesiri, G., Brizi, M., \& Bianchi, G. (2001). Nonalcoholic fatty liver disaes. A feature of metabolic syndrome. Diabetes, 50(8), 1844-1850. https://doi.org/10.2337/diabetes. $\underline{50.8 .1844}$ 
Anjaneyulu, Muragundla, and Kanwaljit Chopra (2004). Quercetin, an anti-oxidant bioflavonoid, attenuates diabetic nephropathy in rats. Clinical and Experimental Pharmacology and Physiology 31.4, 244-248.

Papanas, N., Symeonidis, G., Maltezos, E., Mavridis, G., Karavageli, F., Vosnakidis, T., \& Lakasas, G. (2004). Lakasas, Mean platelet volume in patients with type 2 diabetes mellitus. Platelets, 15(8), 475-478. https://doi.org/10.1080/0953710042000267707

Nakanishi, N. T. S., \& Wada, M. (2005). Association between fasting glucose and Creactive protein in a Japanese population: The Minoh study. Diabete Res. Clinics and Practice, 69, 88-98.

Neam Țu MC1, CrăiȚoiu Ş, Avramescu ET, Margină DM, Băcănoiu MV, Turneanu D, Dănciulescu Miulescu R. (2015). The prevalence of the red cell morphology changes in patients with type 2 diabetes mellitus. Romanian Journal of Morphology and Embryology, 56(1), 183-189.

Ohlson, L. O., Larsson, B., Borntorp, P., Eriksson, H., Svardsudd, K., Welin, L., . . .. (1988). Risk factors for type 2 (non-insulin-dependent) diabetes mellitus. Thirteen and one-half years of folow up of the participants in a study of sweedish men born in 1913. Diabetologia, 31, 798-805. https://doi.org/10.1007/BF00277480

Ohshita, K., Yamane, K., Hanafusa, M., Mori, H., Mito, K., Okubo, M., . . Kohno, N. (2004). Elevated white blood cell count in subjects with impaired glucose tolerance. Diabetes Care, 27(2), 491-496. https://doi.org/10.2337/diacare.27.2.491

Oyedemi, S. O., Yakubu, M. T., \& Afolayan, A. J. (2011). Antidiabetic activities of aqueous leaves extract of Leonotis leonurus in streptozotocin induced diabetic rats. Journal of Medicinal Plants Research, 5, 119-125.

Pagano, G., Pacini, G., Musso, G., Gambino, R., Mecca, F., Depetris, N., . . .. (2002). Nonalcoholic steatohepatitis, insulin resistance, and metabolic syndrome: Further evidence for an etiologic association. Hepatology (Baltimore, Md.), 35(2), 367-372. https://doi.org/10.1053/jhep.2002.30690

Sattar, N. O., Scherbakova, I., Ford, O. R., Eilly, D. S., Stanley, E. A., Forrest, P. W., . . Cobbeand, J. (2004). Shepherd. Elevated alanine aminotransferase predicts new-onset type 2 diabetes independently of classical risk factors metabolic syndrome, and Creactive protein in the west of Scotland coronary prevention study. Diabetes, 53(11), 2855-2860. https://doi.org/10.2337/diabetes.53.11.2855

Sing, M., \& Shin, S. (2009). Changes in erythrocyte aggregation and deformability in diabetes mellitus: A brief review. Indian Journal of Experimental Biology, 47(1), 7-15.

Thomas, M., Maclsaac, R., Tsalamandris, C., .... (2003). Unrecognized anemia in patients with diabetes: A cross sectional survey. Diabetes Care, 26(4), 1164-1169. https://doi.org/ 10.2337/diacare.26.4.1164

Thomas, M. C. (2003). Anemia in diabetes: Marker of mediator microvascular disease. Nature Clinical Practice. Nephrology, 3(1), 20-30. https://doi.org/10.1038/ncpneph0378

Vozarova, B., Weyer, C., Lindsay, R. S., Pratley, R. E., Bogardus, C., \& Tataranni, P. A. (2002). Tataranni PA High white blood cell count is associated with a worsening of insulin sensitivity and predicts the development of type 2 diabetes. Diabetes, 51(2), 455-461. https://doi.org/10.2337/diabetes.51.2.455

Wannamethee, S. G., Shaper, A. G., Lennon, L., \& Whincup, P. H. (2005). Hepatic enzymes the metabolic syndrome and the risk of type 2 diabetes in old men. Diabetes Care, 28(12), 2913-291. https://doi.org/10.2337/diacare.28.12.2913 
Weiss, G., \& Goodnough, L. T. (2005). Anemia of chronic disease. The New England Journal of Medicine, 352(10), 1011-1023. https://doi.org/10.1056/NEJMra041809

Weyer, C., Hanson, K., Bogardus, C., \& Pratley, R. E. (2000). Long-term changes in insulin action and insulin secretion associated with weight gain, loss, regain and maintenance of body weight. Diabetologia, 43(1), 36-46. https://doi.org/10.1007/s001250050005 Zahid, N. (2015). Burden of Diabetes Mellitus in Saudi Arabia. Int J Health Sci (Qassim). Jul; 9(3). V-VI. 